\title{
The SEM Metallography Analysis of Vacuum Cast ZhS6K Superalloy Turbine Blade after Various Working Hours
}

Juraj Belan, Alan Vaško, Lenka Kuchariková, Eva Tillová, Mária Chalupová

Faculty of Mechanical Engineering, Department of Materials Engineering, University of Žilina, Univerzitná 8215/1, 01026 Žilina, Slovak Republic. E-mails: juraj.belan@fstroj.uniza.sk, alan.vasko@fstroj.uniza.sk, lenka.kucharikova@fstroj.uniza.sk, eva.tillova@fstroj.uniza.sk, maria.chalupova@fstroj.uniza.sk

\begin{abstract}
A vacuum cast Ni-base superalloy $\mathrm{ZhS6K}$ is used for the production of turbine blades whose are working in the hot section of turbine in former USSR DV-2 jet engine. The usual working temperature for this kind of alloy is designed for $800 \div 1050^{\circ} \mathrm{C}$. Turbine blades with protective alitized layer made from this alloy were evaluated at the starting stage, then after 600, 1000, 1500 and 2000 hours of regular working. The SEM methods of quantitative metallography were used for structural characteristics evaluation. The microstructural analysis shows increasing of the medium distance of secondary dendrite arms $\mathrm{D}$, what is related to chemical changes in dendritic structure, and the intermetallic strengthening gamma prime phase coarse and turn into spherical shape what leads to decreasing of dislocation and precipitation strengthening mechanism and further decreasing of hot temperature properties of the alloy. The method used at quantitative evaluation and techniques of colour optical microscopy and SEM is useful when microstructure degradation of superalloys has occurred.
\end{abstract}

Keywords: Cast Ni-based superalloy, Vacuum casting, Turbine blades, SEM $\gamma^{\prime}$-phase analysis, Microstructure changes

\section{Introduction}

Superalloys are the primary materials used in the hot portions of jet turbine engines, such as the blades, vanes and combustion chambers, constituting over $50 \%$ of the engine weight. For increasing creep resistance are superalloys produced as cast; with polyedric (equiaxed), directionally solidified or single-crystal structures with fewer grain boundaries. For creep resistance it is important because more grain boundaries (i. e. in wrought alloys) decreasing the creep rupture life. That is the reason for using vacuum induction melting (VIM) method. Vacuum induction melting consists of melting the required components of an alloy under high vacuum and pouring into an ingot or article mould. As referred in [1-2], the use of VIM reduces interstitial gases to low levels, enables higher and more reproducible levels of aluminium and titanium (along with other relatively reactive elements) to be achieved, and results in less contamination from slag or dross formation than air melting. Turbine blades made by this process are typical with polyedric coarse microstructure of austenitic FCC gamma matrix with primary $\mathrm{MC}$ carbides inside of grains and secondary carbides $\mathrm{M}_{23} \mathrm{C}_{6}$ or $\mathrm{M}_{6} \mathrm{C}$ as well at grain boundaries. After hardening the microstructure contains about 20 to $45 \%$ of ordered and coherent $\mathrm{L1}_{2}$ gamma prime $\left(\gamma^{\prime}\right)$ hardening phase (it is for wrought alloys) or as much as $60 \% \gamma^{\prime}$ in cast alloys. The extensive investigations about microstructure-properties relation in superalloys have been made through decades of using in gas turbines. The superalloys became a favourite designers material used in hot section of aero jet engines. As the efficiency demands are increasing thus necessity of better understanding about microstructure, grain boundaries effect and alloying elements influence on high-temperature properties became more significant. Sims et al. have published fundamentals about superalloys metallurgy and microstructure in 1972 and in second edition in 1987 [3]. His work has been extended by the other authors [4-9] who included novelties about directionally solidified, single crystalized, and powder metallurgy produced superalloys. The relation microstructure-mechanical properties at elevated temperatures have been intensively studied by various authors. Rai et. al. [10] has described micromechanism of high-temperature tensile deformation of a directionally solidified superalloy. Sajjadi et. al. [11] has generalized tensile deformation mechanisms at different temperatures in Ni-base superalloy. Caton and Jha [12] have published its work about small fatigue crack growth and failure mode transition in superalloy at elevated temperatures and Huang et. al. [13] describes fatigue crack propagation at elevated temperatures. Zhang et. al. [14] has published study about effect of stress ratio and microstructure on fatigue failure behaviour in polycrystalline superalloy.

There are many methods for the microstructure of superalloys evaluation. The methods of quantitative metallography with coherence testing grids is one of the approaches on how to evaluate the main strengthening phase in Ni-base superalloys alloyed with $\mathrm{Al}$ and $\mathrm{Ti}, \mathrm{Ni}_{3} \mathrm{Al}(\mathrm{Ti}) \gamma^{\prime}$-phase. This phase is responsible for high-temperature stability [15] of alloy due to its high coherency and minimum misfit [16-17] in lattice parameter with FCC $\gamma$ matrix. Its positive role is to prevent dislocation movements even at high temperatures, mostly $\mathrm{Tm}=0.7$ or even higher. However, the long-time high-temperature operation leads to $\gamma^{\prime}$-phase degradation via morphology changing from fine cubic microstructure to coarse near-globular shape or so-called "rafts". The coherent testing grid methods quantify the measured parameters (e.g. intermetallic precipitate $\gamma^{\prime}$ ) and after statistical calculation provides information how the evaluated parameter has changed. This method is very useful in cases when metallography evaluation software have problem with setting the threshold of $\gamma^{\prime}$-phase which is showed in grayscale in micrographs of alloy. The software works only with black and white images and grey-coloured phase, as in this case the $\gamma^{\prime}$ phase, it could not recognize well (is it white or is it black?). However, Szczotok [18] and Szczotok et al. [19] in their 
works show that it is possible to use the metallography software for $\gamma^{\prime}$-phase evaluation, but quality SEM images are necessary with sharp and properly focused view and of course computer with metallography software working with SEM. On the other hands, the identification of $\gamma^{\prime}$-phase via manual evaluation is affected only by user ability. This paper is about application of such methods on ZhS6K Ni-base superalloy and evaluation of dendrite segregation via SDAS factor and $\gamma^{\prime}$-phase after various working periods, 600, 1000, 1500 , and 2000 hours of regular work in DV-2 aero jet engine compared to starting stage microstructure.

\section{Experimental material and methods}

The DV-2 aero jet engine turbine blades of the highpressure turbine (HPT) made from former USSR Ni-base superalloy ZhS6K after 600, 1000, 1500, and 2000 hours of regular work were used as experimental material. This superalloy can be roughly compared to Nimonic class superalloys. The chemical composition of alloy was obtained by optical emission spectrometer, which uses spark

a)
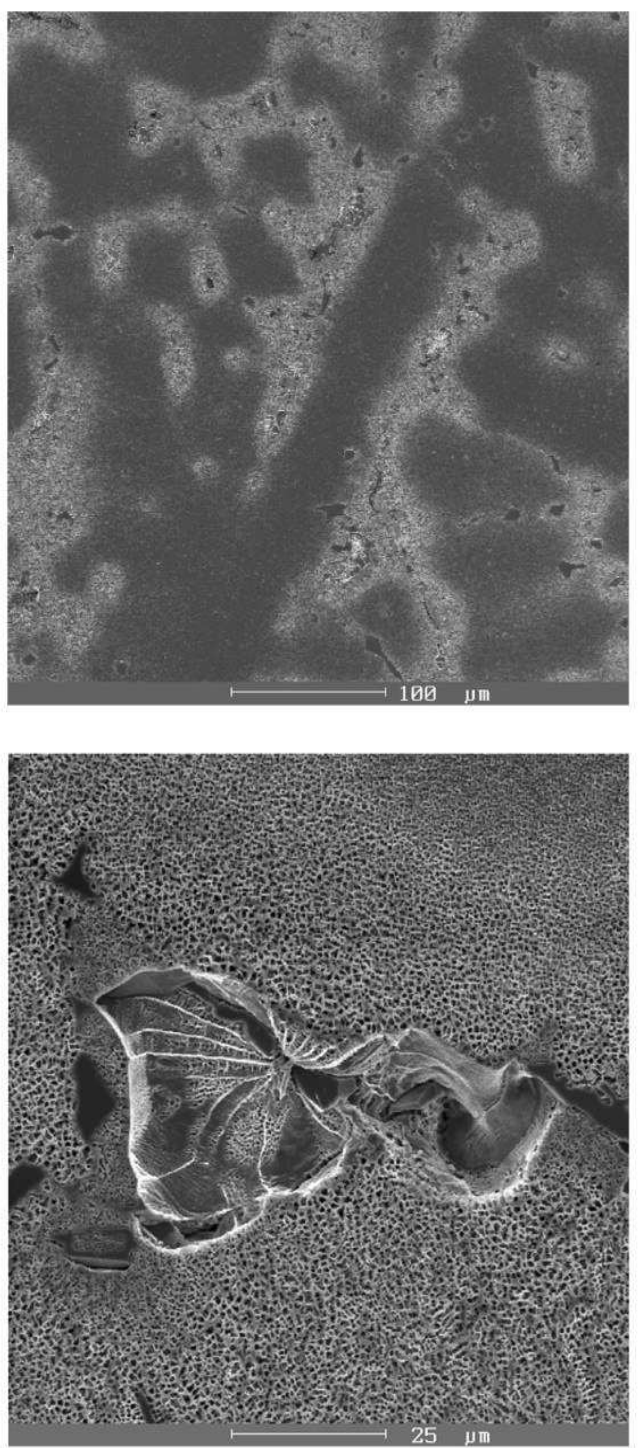

discharge for excitation, SpectroMAXx, Tab. 1.

Tab. 1 The ZhS6k Ni-base superalloy chemical composition in mass volume.

\begin{tabular}{|l|l|l|l|l|l|}
\hline Ni & C & Al & Ti & Cr & Fe \\
\hline 64.7 & 0.202 & 5.22 & 3.05 & 12.44 & 0.192 \\
\hline Co & Mo & W & Si & Sn & B \\
\hline 4.76 & 3.48 & 5.28 & 0.171 & 0.164 & 0.198 \\
\hline
\end{tabular}

This alloy is used for the turbine rotor blade and whole cast small-sized rotors with working temperature from 800 up to $1050{ }^{\circ} \mathrm{C}$. The alloy is made in vacuum furnaces. The temperature of the liquid at casting in vacuum form $1500{ }^{\circ} \mathrm{C} \div 1600{ }^{\circ} \mathrm{C}$, depends on parts shape and amount. Castability of this alloy is very high with only $2 \%-2.5 \%$ shrinkage. Blades made of this alloy are also protected against hot corrosion with protective heatproof alitized layer, so there are able to work at temperatures up to 750 ${ }^{\circ} \mathrm{C}$ for 500 flying hours. Microstructures of HPT blade cast from ZhS6K superalloy are in Fig. 1.

b)
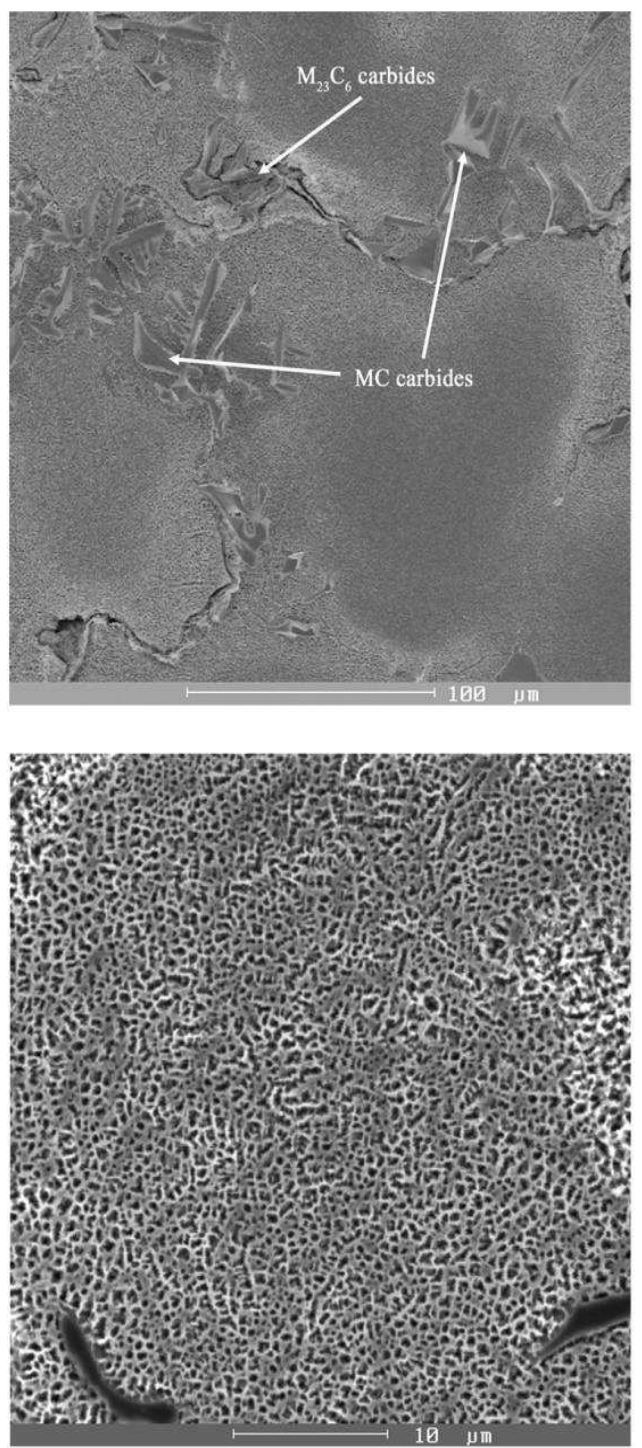

Fig. 1 SEM microstructures of HPT blade made from ZhS6K superalloy; a) dendritic segregation, $b$ ) primary MC and secondary $M_{23} C_{6}$ carbides, c) $\gamma / \gamma^{\prime}$ eutectic cells, and d) strengthening $\gamma^{\prime}$-phase in FCC $\gamma$ matrix, MARBLE etched. 
For SEM metallography observation and EDX analysis were specimens prepared by cutting on MTH Micron 3000 precise saw then mounting into bakelite mixture in Struers Cito-Press 1 and finally ground and polished with using of Struers Tegra-System (TegraPol-15 and TegraForce-1). Grinding and polishing consist of a few steps; grinding with SiC sandpaper No. 320, followed by medium polishing with MD-Allegro and fine polishing with OP-S lubricant (which also act as an active polishing agent).

- After specimen preparation following methods for phase identification and evaluation were used:

- Dendritic segregation was evaluated via secondary dendrite arm spacing (SDAS) factor;

- A coherent testing grid with the various number of probes was used for $\gamma^{\prime}$-phase evaluation; 9 square shape area probes were used for the number of $\gamma^{\prime}$-phase particles evaluation and $50 \mathrm{dot}$ probes made from backslash crossing were used for the volume of $\gamma^{\prime}$-phase particles evaluation. In both cases, the SEM observation was used due to insufficient magnification on the light microscope.

For SDAS factor (Secondary Dendrite Arm Spacing) evaluation was a procedure as shown in Fig. 2 used and the final number of "d" was calculated with Eq. (1). The secondary dendrite arms " $\mathrm{d}$ " distance changing is an important characteristic for describing the base material, matrix $\gamma$, degradation via the equalising of chemical heterogeneity and also grain size growing.

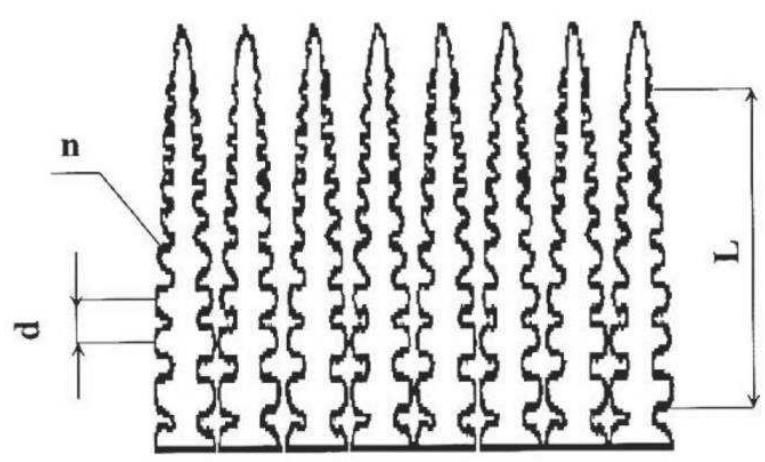

Fig. 2 SDAS factor calculation scheme.

$$
d=\frac{L}{n \times z} \times 1000 \quad(\mu m)
$$

- where " $L$ " is a selected distance on which secondary arms are calculated (the distance is usually chosen with the same value as used magnification " $z$ " - the reason why this is so is in order to simplify the equation), " $n$ " is the number of secondary dendrite arms and " $z$ " is the magnification used.

For the evaluation of the $\gamma$ - and $\gamma^{\prime}$-phases the method of the coherent testing grid was used, and the number of $\gamma^{\prime}$ "N" was evaluated by a grid with 9 square-shaped area probes (Fig. 3a) and the volume of $\gamma^{\prime}$ "V" was evaluated by grid with 50 dot probes (Fig $3 b$ ).

b)

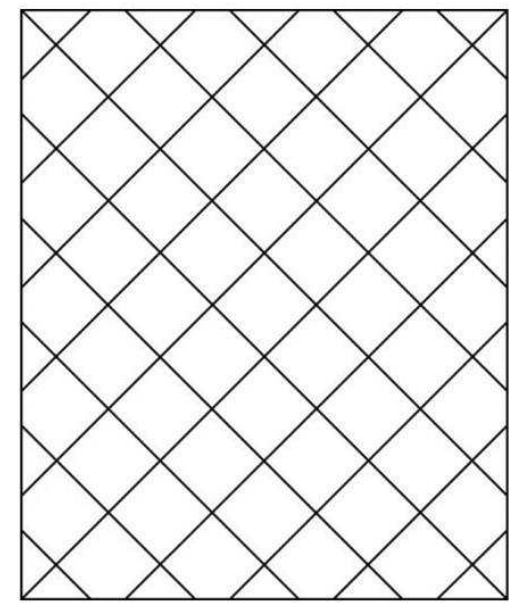

Fig. 3 The $\gamma^{\prime}$-phase amount evaluation - coherent testing grid for a) number of $\gamma^{\prime}$ particles; b) volume of $\gamma^{\prime}$ particles.

Afterwards, the measurement of the values was calculated with Eq. (2) and Eq. (3). For a detailed description of the methods used, see [20-21]. The size of $\gamma^{\prime}$ is also important from the point of view of creep rupture life. A precipitate with a size higher than $0.8 \mu \mathrm{m}$ can be considered to be heavily degraded and as causing decreasing mechanical strength at higher temperatures.

$$
N=1.11 \times z^{2} \times x_{m i d} 10^{-9} \quad\left[\mu m^{-2}\right]
$$

- where "N" is a number of $\gamma^{\prime}$ particles, " $\mathrm{z}$ " is the magnification used, " $x_{\text {mid }}$ " is the medium value of $\gamma^{\prime}$-phase measurements.

$$
V=\frac{n_{s}}{n} \times 100 \quad[\%]
$$

- where "V" is a volume of $\gamma^{\prime}$ particles, " $n_{s}$ " is the medium value of $\gamma^{\prime}$-phase measurement and " $n$ " is a number of dot probes (when using a testing grid with 50 dot probes, the equation become more simple: $V=2 n_{s}$ ). 


\section{Results and discussion}

The turbine blades used in the DV-2 (HPT - HighPressure Turbine) aero jet engine at the starting stage (basic heat treatment) and after an engine exposition (at real working temperatures) for 600, 1000, 1500 and 2000 hours were used for SDAS factor calculation. The results of the evaluation are in Tab. 2 and the microstructures are in Fig. 4.

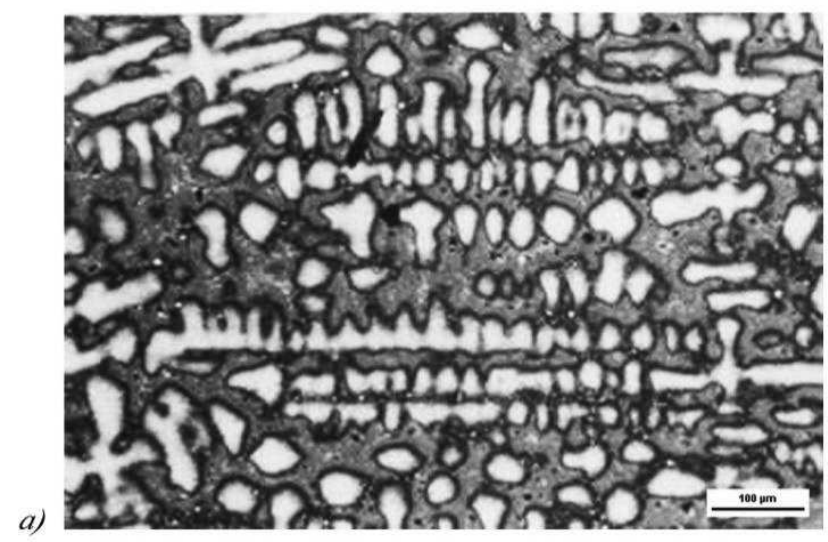

Fig. 4 Dendritic segregation of ZhS6K turbine blades: a) starting stage; b) after 1500 hrs. of work, Marble etchant.

Dendritic segregation occurs during the solidification of all superalloys. The solidification region consists of a zone where the alloy is partially solid and partially liquid (the liquid + solid zone). The solidification mode is generally dendritic and the first (primary) dendrites to form are lower in precipitate-forming elements ( $\mathrm{Ti}, \mathrm{Al}, \mathrm{Nb}$, and C) than the average melt composition. The interdendritic areas are correspondingly enriched in these solute elements. As cooling rates become slower, the primary dendrites and interdendritic regions become larger. The slower the cooling rate and the more highly alloyed the melt, the larger the interdendritic regions. At some point, the interdendritic regions become large enough to interconnect and form macroscale defects. Driven by density differences between the solute-rich interdendritic liquid and the nominal melt composition, these regions become self-perpetuating continuous channels in the solidification structure. Such channel defects may grow vertically (but not truly perpendicular) from the solidification front for low-density interdendritic fluids or may grow horizontally (parallel) to the solidification front for high-density interdendritic liquids. Solute-rich channel defects are referred to as "freckles" because, when viewed in a crosssection perpendicular to their growth axis, they are seen as round, dark, circular spots. Freckle regions may form hard intermetallic compounds that cannot be removed by subsequent processing [1]. Tang et al. [22] in his work reports the significance of dendrite arm spacing in relation to the coarsening of $\gamma^{\prime}$-phase and its thermal stability. Shows that $\gamma^{\prime}$ particle situated in primary dendrite arm except coarsening has partially coalesced after 100 hours thermal exposition but on the other hand, $\gamma^{\prime}$-phase rarely coalesced in interdendritic region after thermal exposition for the same time. Coalescence became evident in the primary dendrite arms after 500 hours while $\gamma^{\prime}$-phase almost
Tab. 2 Results of SDAS factor for real turbine blades, heat-treated ZhS6K alloy.

\begin{tabular}{|l|l|}
\hline Type of blade & $\begin{array}{l}\text { Secondary dendrite arm-spacing } \\
{[\boldsymbol{\mu m}]}\end{array}$ \\
\hline starting stage & 24.4 \\
\hline 600 hrs. & 24.8 \\
\hline 1000 hrs. & 28.0 \\
\hline 1500 hrs. & 48.7 \\
\hline 2000 hrs. & 66.6 \\
\hline
\end{tabular}

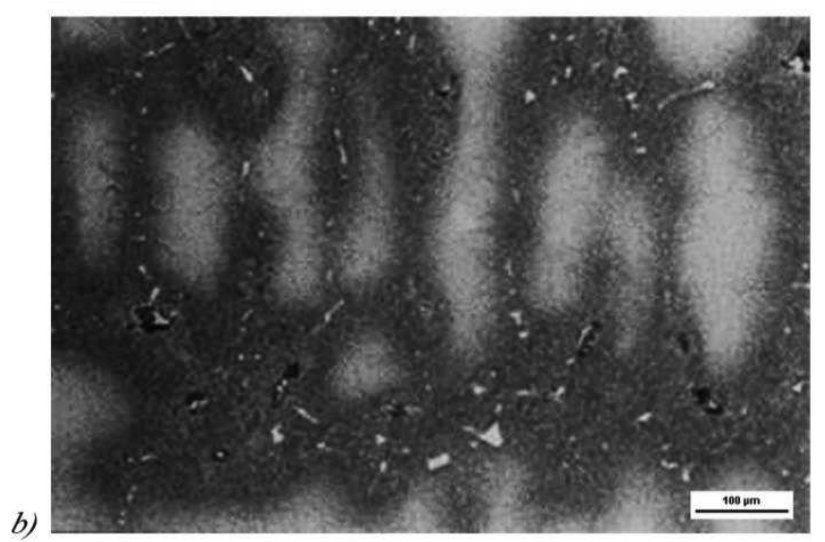

keep cubic in the interdendritic regions without any significant signs of coalescence. Fig. 5 shows the average $\gamma^{\prime}$ phase size for primary dendritic arm and the interdendritic region.

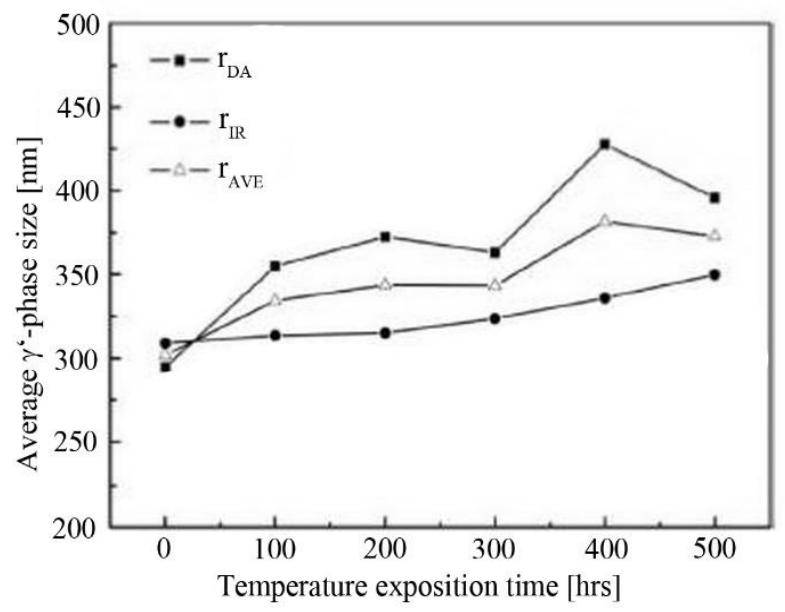

Fig. 5 The relation between average $\gamma^{\prime}$-phase size and temperature exposition time for primary dendritic arm $r_{D A}$ and interdendritic region $r_{I R}$. The $r_{A V E}$ is the mean value of the two [22].

Results from Fig. 5 confirm the statement about $\gamma^{\prime}$ phase forming elements are rich in the interdendritic regions due to residual chemical segregation. On the other hand, the average $\gamma^{\prime}$-phase particle size in primary dendritic arms is always larger compared to interdendritic regions after temperature exposition exceeds 100 hours, Fig. 5 [22]. The $\gamma^{\prime}$-phase size evaluation on turbine blades with using of coherent testing grids is in Tab. 3. The micrographs related to this evaluation are documented in Fig.6a-d. 
Tab. 3. The $\gamma^{\prime}$-phase evaluation results on heat-treated turbine blades at various working times.

\begin{tabular}{|l|l|l|l|}
\hline $\begin{array}{l}\text { Time of work } \\
\text { [hours] }\end{array}$ & $\begin{array}{l}\text { Number of } \boldsymbol{\gamma}^{\prime} \text {-phase } \\
\mathbf{N}\left[\boldsymbol{\mu m}^{-2}\right]\end{array}$ & $\begin{array}{l}\text { The volume of } \boldsymbol{\gamma}^{\prime} \text {-phase } \\
\mathbf{V}[\%]\end{array}$ & $\begin{array}{l}\text { The average size of } \boldsymbol{\gamma}^{\prime} \text {-phase } \\
\mathbf{u}\left[\boldsymbol{\mu} \mathbf{m}^{2}\right]\end{array}$ \\
\hline $\mathbf{0}$ & 0.99 & 67.2 & 0.68 \\
\hline $\mathbf{6 0 0}$ & 1.12 & 67.6 & 0.6 \\
\hline $\mathbf{1 0 0 0}$ & 1.1 & 59 & 0.54 \\
\hline $\mathbf{1 5 0 0}$ & 0.82 & 57.4 & 0.7 \\
\hline $\mathbf{2 0 0 0}$ & 0.69 & 40.6 & 0.58 \\
\hline
\end{tabular}

The $\gamma^{\prime}$-phase morphology at the starting stage is cuboid and distributed equally in the base $\gamma$ matrix (Fig. 1d). The $\gamma^{\prime}$-phase morphology changed with an increase of the hours of work at a temperature of up to $750{ }^{\circ} \mathrm{C}$. The particles of the $\gamma^{\prime}$-phase gradually coarsen (works up to 1000 hours, Fig. 6b), which confirms the results of a number of $\gamma^{\prime}$-phase evaluations "N" (see Tab. 3). A decrease of this value at a longer duration of work (1500 and 2000 hours) is caused by re-precipitation of new, fine $\gamma^{\prime}$-phase particles in the area between the primal $\gamma^{\prime}$-phase (Fig. 6d).

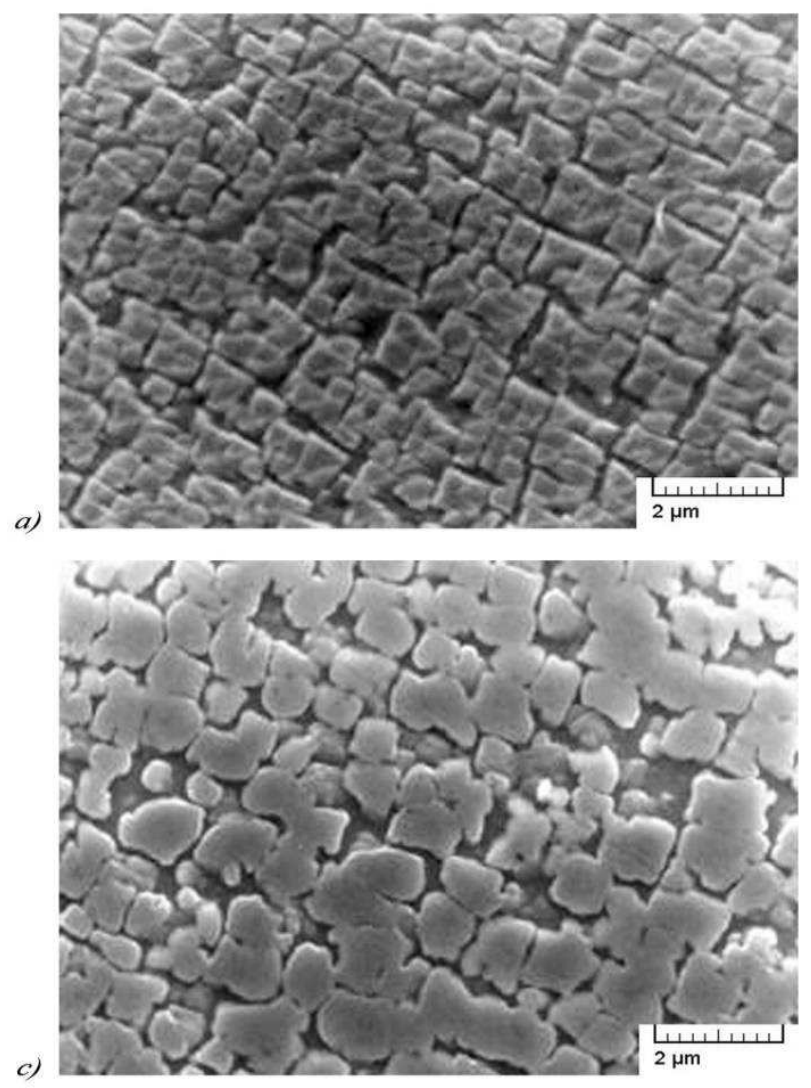

From the results in TABLE 3 , it is obvious that the $\gamma^{\prime}$ phase of the ZhS6K alloy coarsen uniformly and increase its volume ratio in the structure after up to 1000 hours of exposition (regular work of a jet engine). However, after longer durations of work (1500 or 2000 hours) there occurs the re-precipitation of new, fine particles of the $\gamma^{\prime}$ phase in the free space of matrix and which has caused structural heterogeneity.
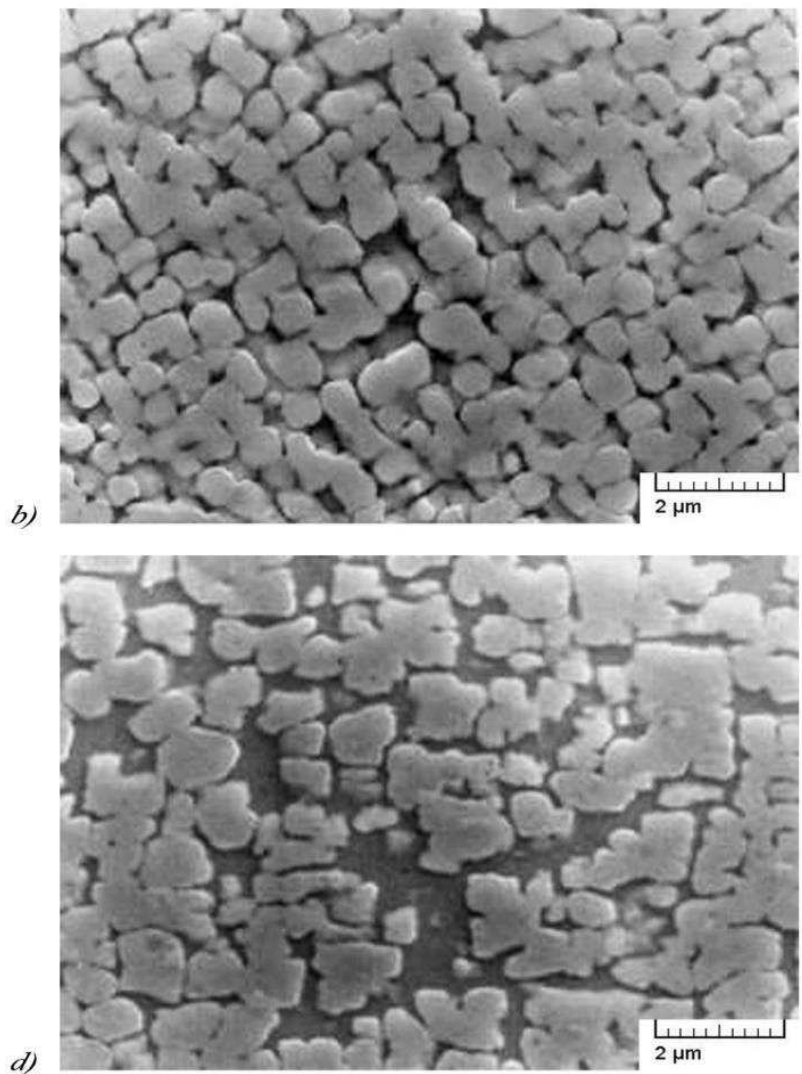

Fig. 6 Detail of the ZhS6K alloy's $\gamma^{\prime}$-phase showing the increasing distance between $\gamma^{\prime}$ particles as an effect of working exposition - at normal working loading of a jet engine - which has a significant influence on the dislocation hardening effect; a) 600 hrs., b) 1000 hrs., c) $1500 \mathrm{hrs,} \mathrm{and} \mathrm{d)} 2000 \mathrm{hrs.}, \mathrm{HCl}+\mathrm{H}_{2} \mathrm{O}_{2}$ etchant.

In terms of structure degradation and the prediction of the lifetime of turbine blades - as well as the jet engine itself - and according to the results in Tab. 3, after up to 1000 hours of exposition the structure (with " $\mathrm{N}$ " = 1.1004 , "V" $=59$ and average size "u" $=0.53615$ ) is at the "edge" of use because of its mechanical properties, as referred by Cetel and Duhl [22]. They reported, that $\gamma^{\prime}-$ phase optimum size $0.35-0.45 \mu \mathrm{m}$ is an optimum size for satisfactory creep rupture strength. Murakumo et al. [24] have described the influence of $\gamma^{\prime}$-phase volume on creep rupture life. They pointed out that the longest creep rupture life was obtained with the $70 \%$ of $\gamma^{\prime}$-phase volume at $900^{\circ} \mathrm{C}$ and $55 \%$ of $\gamma^{\prime}$-phase volume at $1100^{\circ} \mathrm{C}$, Fig. 7 . They have also assumed a different creep mechanism for $900^{\circ} \mathrm{C}$ and $1100^{\circ} \mathrm{C}$. It means that initial microstructure after heat-treatment remain stable longer at temperature $900^{\circ} \mathrm{C}$ and is effective for strengthening at this temperature to prevent the dislocation movement by producing 
narrower $\gamma$ matrix channel without eutectic $\gamma^{\prime}$-phase region. The dependence of the creep rupture life on the volume of $\gamma^{\prime}$-phase is more evident in single-crystal than in polycrystalline superalloys.

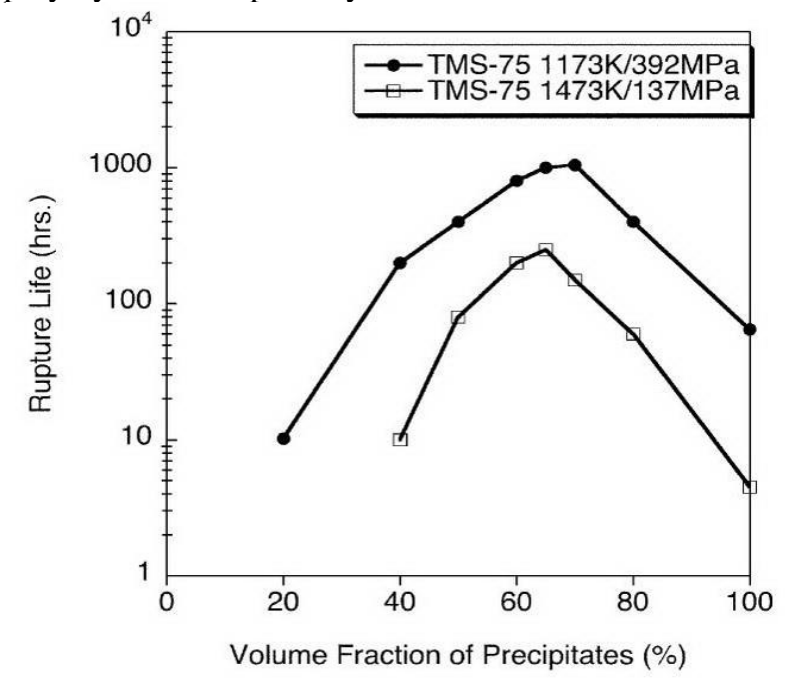

Fig. 7 Relationship between $\gamma^{\prime}$-phase volume and creep rupture life [24].

Work performed by Nathal et al. [25] indicates that the optimum $\gamma^{\prime}$-phase size for an alloy creep rupture life is dependent on the lattice mismatch between the $\gamma$ - and $\gamma^{\prime}$-phases, which is composition-dependent, Fig. 8.

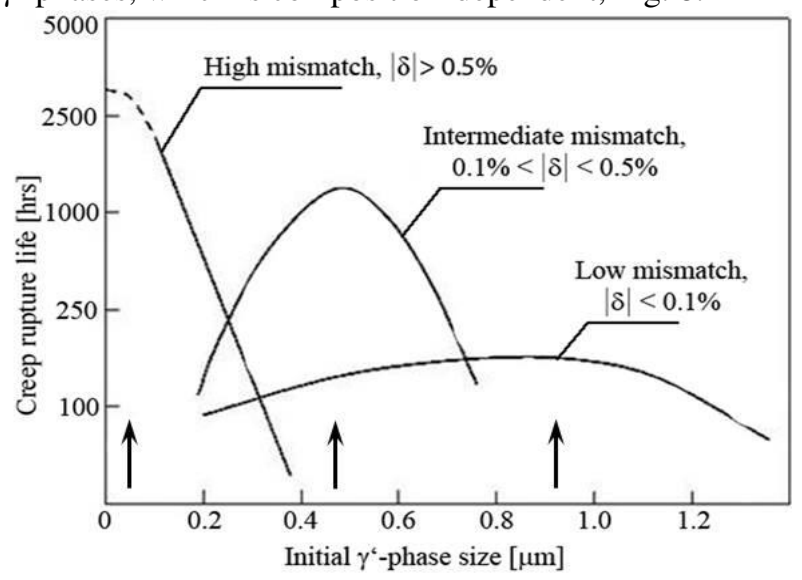

Fig. 8 The optimum $\gamma^{\prime}$-phase size to maximize creep strength is dependent on mismatch between the $\gamma$-and $\gamma^{\prime}$-phases [25].

The $\gamma^{\prime}$-phase particles with higher diameter or size significantly decreases high-temperature properties of superalloys. However, the $\gamma^{\prime}$-phase size is not the only parameter influencing the lifetime. In addition, the number "N" and volume "V" is important from the point of view of dislocation hardening. When " $\mathrm{N}$ " and " $\mathrm{V}$ " are smaller, this means that the distances between single particles are greater and that fact causes a decrease of the dislocation hardening effect.

\section{Conclusion}

For aero jet engine DV-2 turbine blades made from Ni-base superalloy ZhS6K after the various time of loading $600,1000,1500$, and 2000 hours at regular operation condition the methods of quantitative metallography were used for microstructure evaluation. After applying of quantitative metallography methods characteristics as SDAS factor, the volume of $\gamma^{\prime}$-phase "V", number of $\gamma$ 'phase "N" and $\gamma$ '-phase particles size were calculated.

- Increasing values of SDAS factor shows the influence of high-temperature operation on equalizing the chemical composition between dendrite core and interdendritic areas what leads to the production of new fine $\gamma^{\prime}$-phase particles and at the same time coarsening of already presented $\gamma^{\prime}$-phase particles.

- Coarsening of $\gamma^{\prime}$-phase results into significant decreasing of creep rupture life of ZhS6K superalloy and decreasing the engine operation lifetime as well. The limit number of operation hours according to analysis is 1000 hours where $\gamma^{\prime}$-phase size is $0.53 \mu \mathrm{m}$. With $\gamma^{\prime}$-phase size higher than this value creep rupture and hightemperature properties of superalloy decreases due to loss of $\gamma / \gamma^{\prime}$ coherency, increasing the misfit parameter and precipitation hardening effect too.

\section{Acknowledgement}

This work was supported under the project of Operational Program Research and Innovation: Research and development activities of the University of Žilina in the Industry of 21st century in the field of materials and nanotechnologies, No. 313011T426. The project is cofunding by European Regional Development Fund. The

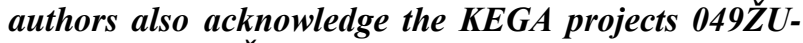
4/2017 and 012ŽU-4/2019 for the financial support of this work.

\section{References}

[1] DAVIS, J., R. (2000). ASM Specialty handbook Nickel, Cobalt and their alloys, ASM International, Ohio, USA.

[2] CAMPBELL, F., C. (2006). Manufacturing Technology for Aerospace Structural Materials, Elsevier Ltd, Amsterdam, NL.

[3] SIMS, Ch., T., STOLOFF, N., S., HAGEL, W., C. (1987). Superalloys II, 2nd ed., Wiley-Interscience, USA.

[4] DURAND-CHARE, M. (1997). The microstructure of superalloys, Gordon \& Breach Science Publishers, Amsterdam, NL.

[5] DAVIS, J., R. (2001). Superalloys. In: Alloying: Understanding The Basics (J.R. Davis (Ed.)), ASM International, Ohio, USA.

[6] DONACHIE, M., J., DONACHIE, S., J. (2002). Superalloys - A technical Guide (2nd edition), ASM International, Ohio, USA. 
[7] REED, C. R. (2006). The superalloys. Fundamentals and applications, Cambridge University Press, New York, USA.

[8] GADDES, B., LEON, H., HUANG, X. (2010). Superalloys - Alloying and Performance, ASM International Publication, Ohio, USA.

[9] DAŇA, M., ZETKOVÁ, I., MACH, J. (2018). Mechanical properties of Inconel alloy 718 produced by 3D printing using DMLS. In. Manufacturing Technology, Vol. 18, No. 4, pp. 559 - 562, J. E. Purkyne University in Usti nad Labem.

[10] RAI, R., K., SAHU, J., K., Jena, P., S., M., DAS, S., K., PAULOSE, N., FERNANDO CHANDRU, D. (2018). Micromechanism of High-Temperature Tensile Deformation Behavior of a Directionally Solidified Nickel Base Superalloy. In. JMEPEG, Vol. 27, No. 2, pp. 659 - 665, ASM International.

[11] SAJJADI, S., A., NATEGH, S., ISAC, M., ZEBARJAD, S., M. (2004). Tensile deformation mechanisms at different temperatures in the $\mathrm{Ni}$ base superalloy GTD-111. In. J. Mater. Process. Technol., Vol. 155 - 156, pp. 1900 - 1904, Elsevier B.V.

[12] CATON, M., J., JHA, S., K. (2010). Small fatigue crack growth and failure mode transitions in a Nibase superalloy at elevated temperature. In. Int. J. Fatigue, Vol. 32, No. 9, pp. 1461 - 1472, Elsevier Ltd.

[13] HUANG, X., WANG, L., HU, Y., GUO, G., SALMON, D., LI, Y., ZHAO, W. (2016). Fatigue crack propagation behavior of Ni-based superalloys after overloading at elevated temperatures. In. Progr. Nat. Sci. Mat. Int., Vol. 26, No. 2, pp. 197 - 203, Chinese Materials Research Society.

[14] ZHANG, H., GUAN, Z., W., WANG, Q., Y., LIU, Y., J., LI, J., K. (2018). Effects of Stress Ratio and Microstructure on Fatigue Failure Behavior of Polycrystalline Nickel Superalloy. In. JMEPEG, Vol. 27, No. 5, pp. 2534 - 2544, ASM International.

[15] ANTOLOVICH, S., D. (2015). Microstructural aspects of fatigue in Ni-base superalloys. In. Phil. Trans. R. Soc., Vol. A 373, pp. 1 - 36, The Royal Society Publishing.

[16] LIU, Ch., LI, Y., ZHU, L., SHI, S. (2018). Effect of Coherent Lattice Mismatch on the Morphology and Kinetics of Ordered Precipitates. In. JMEPEG, Vol. 27, No. 9, pp. 4968 - 4977, ASM Internatioanl.
[17] DIOLOGENT, F., CARON, P., d'ALMEIDA, T., JACQUES, A., BASTIE, P. (2003). The $\gamma / \gamma^{\prime}$ mismatch in $\mathrm{Ni}$ based superalloys: In situ measurements during a creep test. In. Nucl. Instrum. Methods Phys., B 200, pp. 346 - 351, Elsevier Ltd.

[18] SZCZOTOK, A. (2017). Metallographic study of the casting made from cmsx-6 sc nickel-based superalloy. In. Arch.Metall. Mater., Vol. 62, No. 2, pp. 581 - 586, Institute of Metallurgy and Materials Science of Polish Academy of Sciences, Committee on Metallurgy of Polish Academy of Sciences.

[19] SZCZOTOK, A., PIETRASZEK, J., RADEK, N. (2017). Metallographic study and repeatability analysis of $\gamma^{\prime}$ phase precipitates in cored, thinwalled castings made from in713c superalloy. In. Arch. Metall. Mater., Vol. 62, No. 2, pp. 595 601, Institute of Metallurgy and Materials Science of Polish Academy of Sciences, Committee on Metallurgy of Polish Academy of Sciences.

[20] BELAN, J. (2013). Study of advanced Ni-base ŽS6K alloy by quantitative metallography methods. In. Manufacturing Technology, Vol. 13, No. 1, pp. $2-7$, J. E. Purkyne University in Usti nad Labem.

[21] BELAN, J. (2012). Study of advanced materials for aircraft jet engines using quantitative metallography. In: Recent Advances in Aircraft Technology (R.K. Agarwal (Ed)), pp. 49 - 74. Rijeka: InTech.

[22] TANG, S., ZHENG, Z., NING, L., K. (2014). Gamma prime coarsening in a nickel base single crystal superalloy. In. Materials Letters, Vol. 128 , pp. 388 - 391, Elsevier B.V.

[23] CETEL, A., D., DUHL, D., N. (1988). Microstructure-Property Relationships In Advanced Nickel Base Superalloy Airfoil Castings. In. 2nd International SAMPE Metals Conference, $\mathrm{pp}$. $37-48$, USA.

[24] MURAKUMO, T., KOBAYASHI, T., KOIZUMI, Y., HARADA, H. (2004). Creep behaviour of Ni-base single-crystal superalloys with various $\gamma^{\prime}$ volume fraction. In. Acta Materialia, Vol. 52, pp. 3737 - 3744, Elsevier Ltd.

[25] NATHAL, M., V. (1987). Effect of initial gamma prime size on the elevated temperature creep properties of single crystal nickel base superalloys. In. Metallurgical Transaction A, Vol. 18, No. 11, pp. 1961 - 1970, Springer-Verlag. 